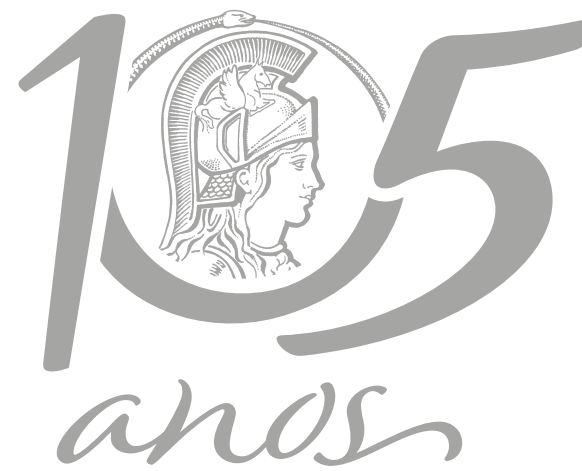

$1916 \cdot 2021$

\title{
Comments on convenience authorship
}

\author{
ALEXANDER W.A. KELLNER
}

The world is currently still under the impact of the pandemic, with negative global effects that have collapsed the health system in several states (e.g., Melo et al. 2020). Even though in some regions the pandemic appears to be starting to come under control, this is not the case in most countries, providing uncertainty about the future scenarios (e.g., Bitar \& Steinmetz 2020).

One of the side effects of Covid-19 was the increase in scientific article submissions, leading to concerns about the quality of published research (e.g., Bauchner et al. 2020). While discussion of this matter is legitimate, there are other issues to be addressed, such as the increasing number of authors in papers (e.g., Bandodkar \& Grover 2016), a potential problem that should also be on the editors' radar.

Discussing authorship is perhaps one of the most complex topics in science and there is some literature about it (e.g., Rogers 1999), occasionally resulting in pretty straight-forward recommendations (e.g., Shewan \& Coats 2010). McNutt et al. (2018) have outlined some suggestions regarding authorship policies of scientific periodicals, pointing out the existence of at least four detrimental practices. The most common of these is called guest authorship (sometimes also referred to as honorific or gift authorship), and occurs when someone of high status, whether in the field or in the institution, is invited to sign the paper without having actually provided any contribution. While no real harm is intended by such actions, there seems to be little doubt that these situations are reprehensible to those who offer and those who accept them.

Ghost authorships, in which individuals who actually contributed to the article but do not sign it to hide a conflict of interest, are particularly complex, since these are difficult cases to be proven, and may even be caused by the manipulation of the authors. Special attention should be given to reviewers who may try to steer the study in different directions that have nothing to do with the scientific content of the article (sometimes even peripheral to the research), aiming to reinforce their own convictions (and publications) or detract from the work of other authors, while hiding under anonymity. In later articles, these same reviewers may even cite the work they reviewed as evidence against that of those with competing ideas.

The two remaining categories of problematic authorship listed by McNutt et al. (2018) are orphan authorships, when authors are just "left out" of the paper for unfair reasons, and forged authorship, when authors who were not part of the original study are added without their knowledge. In the latter, such action could even 
be taken to increase the chances of getting the paper published. In both cases, demonstrating these situations should be, for the most part, very easy to detect, leaving editors with the possibility of a wide range of measures, of which retraction of the article tends to be the best course of action.

There is, however, another category of authorship that appears more problematic and seems to be increasing: the convenience authorship, briefly introduced by Kellner (2018). Convenience authorship can be defined as the reciprocal action that takes place between researchers when one invites the other to appear in her/his article without effective contribution, with the aim of inflating the number of publications of each one. This procedure differs from honorific authorship because this inclusion is not linked to any reverence to the included author, nor to giving more importance to the study. It is also not linked to forged authorship, as it is consensual among those who practice it and there is no attempt to amplify the relevance of the study considering that there is usually an equivalence of the author included in the field with the one who made the inclusion.

It can be noted that there is an increasing number of young scientists publishing articles with colleagues from different laboratories (sometimes from the same institution) on topics that are not directly related to what they were actually trained to do. Although clearly some (perhaps most) of these collaborations are legitimate and even necessary, particularly in multidisciplinary research where knowledge of different areas is fundamental for the study, there is also the possibility of researchers reciprocating authorship without a clear purpose other than that of increasing individual scientific production. And that can start very early in the career.
There are laboratories with publication policies where all members (sometimes also including all technicians) participate in all (or most) of the papers published by that lab. This results in graduate students "collaborating" with each other on research activities sometimes unrelated to the topic they are developing in their dissertations or theses. There are other laboratories where publication policies only reward authorship for those who actually contributed to the study. The head of the lab encourages teamwork among students, each one developing their own piece of research that is combined and included in the final manuscript. But here is the problem. It is very common for students to undertake internships in laboratories when they are still taking undergraduate classes. With the continuation of their career, upon entering a graduate program, they often have the possibility to choose between the laboratories to carry out their research. At this point, they face the following dilemma: starting in a place where everyone is systematically included in every article published just because they are part of the lab or joining another group where they must use considerable research time to be included in an article. While generalizations are always delicate, there is a tendency for a student who works in a lab where everyone "gets all" might eventually end up with more publications in their curriculum.

But that is not all. Regardless of what anyone may think, the fact is that the amount of publications seriously influences the chances of getting a job. Yes, there are selection com mittees that understand the problematic of numbers (and, by the way, of bibliometric indexes as well), but the fact is that the prospect of candidates with more publications to be selected for the job are greater. And this is where another aspect of this problem lies: what kind of publishing policy is this now-employed young scientist, 
having been favored by more papers to get the position, going to adopt in his own lab, now that he is "the boss"?

As pointed out, discussing authorship is one of those unpleasant topics that can too quickly lead to wrong conclusions. However, problems linked to publication have to be taken to graduate students (e.g., Krokoscz \& Ferreira 2019), who need some guidance. Regarding convenience authorship, there are countless reasons for collaborations that result in multiple constructive accomplishments, and there is no doubt that science is moving in this direction. The reasons for having multiple authors in an article include (but are not limited to) the general improvement of research, the exchange of experiences between different institutions or researcherswith differentacademicbackgrounds, the transfer of knowledge between experienced and less experienced scientific centers, and the opening of new research opportunities. But in times of scientific denialism, clearly exposed by the current pandemic, there is no doubt that actions preventing misconduct in science are needed, including addressing the issue of conceding correct authorship to those who deserve it. Granted, it is unclear how to handle and avoid authorship of convenience, particularly given the escalation of excessive pressure on students and young scientists towards publications that, even if ignored or downplayed, is just there. Great care must also be taken not to introduce rules that inhibit the interaction of researchers to achieve better and more consistent results than if each one acted independently. This would be a dangerous disservice to science and must be avoided at all costs. On the other hand, it has to be made clear to the new generation of researchers that the simple "adding authorship strategy" to burst their publications is not the correct way to go and carries negative ethical implications that will accompany them throughout their entire career.

Hopefully alternatives can be found, as it would be sad to have to surrender that convenience authorship has become an adaptive strategy for students and young researchers to "stay in business".

\section{REFERENCES}

BANDODKAR NR \& GROVER V. 2016. Factors Influencing the Extent of Co-Authorship in IS Research: An Empirical Investigation. Commun Assoc Inf Syst 38: 84-105. DOI: 10.17705/1CAIS.03803.

BAUCHNER H, FONTANAROSA PB \& GOLUB RM. 2020. Editorial Evaluation and Peer Review During a Pandemic How Journals Maintain Standards. JAMA 324: 453-454. doi:10.1001/jama.2020.11764.

BITAR S \& STEINMETZ WA. 2020. Scenarios for the Spread of COVID-19 in Manaus, Northern Brazil. An Acad Bras Cienc 92: e20200615. DOI 10.1590/0001-3765202020200615.

KELLNER AWA. 2018. Autoria de conveniência. Pesquisa FAPESP 268: 6.

KROKOSCZ M \& FERREIRA SMSP. 2019. Perceptions of Graduate Students at the University of São Paulo about Plagiarism Practices in Academic Works. An Acad Bras Cienc 91: e20180196. DOI 10.1590/0001-3765201920180196.

MCNUTT MK ET AL. 2018. Transparency in authors' contributions and responsibilities to promote integrity in scientific publication. Proc Natl Acad Sci USA 115: 25572560. https://doi.org/10.1073/pnas.1715374115.

MELO CML, SILVA GAS, MELO ARS \& FREITAS AC. 2020. COVID-19 pandemic outbreak: the Brazilian reality from the first case to the collapse of health services. An Acad Bras Cienc 92: e20200709. DOI 10.1590/0001-3765202020200709.

ROGERS LF. 1999. Salami Slicing, Shotgunning, and Ethics of Authorship. AJR AM J Roentgenol 173: 265.

SHEWAN LG \& COATS AJ. 2010. Ethics in the authorship and publishing of scientific articles. Int J Cardiol 144: 1-2.

\section{How to cite}

KELLNER AWA. 2021. Comments on convenience authorship. An Acad Bras Cienc 93: e2021933. DOI 10.1590/0001-37652021933. 


\section{ALEXANDER W.A. KELLNER}

https://orcid.org/0000-0001-7174-9447

Laboratório de Sistemática e Tafonomia de Vertebrados

Fósseis, Departamento de Geologia e Paleontologia

do Museu Nacional/UFRJ, Quinta da Boa Vista, s/n,

São Cristóvão, 20940-040 Rio de Janeiro, RJ, Brazil

E-mail:kellner@mn.ufrj.br

\section{(cc) BY}

